\title{
Implementing Guided-Discovery Grammar Learning ${ }^{1}$
}

\section{(La Implementación del aprendizaje de la gramática por descubrimiento guiado)}

\author{
Daniela Achoy Solano² \\ Universidad Nacional, Costa Rica
}

\begin{abstract}
This inquiry explores the implementation of guided discovery as a means to promote analyzing and reasoning skills in the study of grammar in the English as a Foreign Language (EFL) class. A grammar guided discovery learning-based action plan was analyzed based. This study acknowledges the need to develop analytical and reasoning skills when learning grammar and highlights the relevance of reflecting upon current teaching practices to attain effective grammar learning.

\section{RESUMEN}

Esta investigación explora la implementación del aprendizaje por descubrimiento guiado para promover habilidades de análisis y razonamiento al estudiar gramática, en cuanto al inglés como lengua extranjera Se analiza un plan de acción basado en el aprendizaje de gramática por descubrimiento guiado. Se plantea la necesidad de desarrollar habilidades de análisis y razonamiento en el aprendizaje de la gramática y se destaca la importancia de reflexionar durante las prácticas de enseñanza para lograr un eficaz aprendizaje gramatical.
\end{abstract}

1 Recibido: 31 de julio de 2019; aceptado: 3 de febrero de 2020.

2 Escuela de Literatura y Ciencias del Lenguaje. Correo electrónico: daniela.achoy.solano@una.cr

Letras 68 (2020), ISSN 1409-424X; eISSN 2215-4094 
Keywords: English as a foreign language, guided discovery, analyzing skills, reasoning skills, grammar learning

Palabras claves: inglés como lengua extranjera, descubrimiento guiado, habilidades de análisis, habilidades de razonamiento, aprendizaje gramatical

\section{Introduction}

In the field of English as a Foreign Language (EFL), current teaching practices are often characterized as being student-centered by allowing learners to become more active and participative in their own learning process. However, when it comes to learning grammar, students are mostly used to following explicit teacher explanations rather than discovering by themselves. Grammar instruction has been, then, focused on the educator's direct explanations and not on the development of analysis and reasoning skills in language learners. In an effort to move from teacher-oriented grammar instruction to a more student-centered setting, guided discovery ${ }^{3}$ plays a central role. As Glaser explains, guided discovery facilitates learning throughout an assisted discovery process in which learners are guided to find patterns and construct grammatical rules on their own. ${ }^{4}$

The motivation for conducting this study stems from a previous instructor-researcher reflective process in which the need for having students learn the grammatical contents by themselves with the educator's guide was evident. Therefore, the present study is based on action research intended to improve the instructor-researcher's teaching, and consequently, the students' learning ${ }^{5}$ of grammar within the EFL class. Thus, the aim of this paper is to foster analysis and

3 Wilfried Decoo, "The Induction-Deduction Opposition: Ambiguities and Complexities of the Didactic Reality," IRAL: International Review of Applied Linguistics 34, 2 (1996): 95-118 (97). DOI: https://doi.org/10.1515/iral.1996.34.2.95.

4 Karen Glaser, Inductive or Deductive? The Impact of Method of Instruction on the Acquisition of Pragmatic Competence in EFL (Newcastle: Cambridge Scholars, 2014) 70.

5 David Tripp, "Action Research: A Methodological Introduction," Educação e Pesquisa 31, 3 (2005): 433-466. DOI: http://dx.doi.org/10.1590/S1517-97022005000300009. 
reasoning skills through the implementation of guided discovery in English learners at a Costa Rican state university to achieve an autonomous and effective grammar learning process.

For an understanding of students' perceptions about learning English grammar and about their previous learning experiences, a questionnaire was administered at the beginning of the study. Since action research is action plan-based, ${ }^{6}$ the action plan for the purposes of this inquiry followed the core tenets of guided discovery to develop analytical abilities and reasoning skills. Once the plan of action was implemented, its outcomes in terms of the educator's instruction, the students' performance, and the teaching materials used were reflected upon. After having instructed the learners on using guided discovery, their perspectives were also examined at the end of the study. By and large, the results suggest that fostering constant reflection during the implementation of guided discovery not only strengthened and improved the instructor-researcher's grammar teaching practices but also impacted the students' grammar learning.

\section{Theoretical Groundings}

\section{Guided Discovery Learning}

The grammatical component of the English language has been taught through two opposing instructional approaches: deductive and inductive grammar teaching approaches. ${ }^{7}$ According to Thornbury, a deductive approach, also referred as rule-driven learning, presents the target rule accompanied with examples of its application to

6 Antonio Latorre, "La Investigación-Acción," La Investigación-Acción: conocer y cambiar la practica educativa (Barcelona: Grao, 2013) 42.

7 Elham Mahjoob, "A Comparison of the Effectiveness of Inductive vs. Deductive Instruction of Grammar to EFL Students," Journal of Language, Linguistics and Literature 1, 5 (2015): 164-169 (165); and Handoyo Puji Widodo, "Approaches and Procedures for Teaching Grammar," English Teaching: Practice and Critique 5,1 (2006): 122-141 (125). 
explain and study grammar. ${ }^{8}$ This requires explicit knowledge of rules and patterns, known as conscious learning (Klein, 1986), to understand the language and gain proficiency ${ }^{9}$. In brief, following deductive teaching primarily entails presenting the grammatical contents explicitly for the learners to be able to practice and apply the rules.

Implementing deductive teaching in EFL settings may limit learners' initiative to construct and shape their own grammatical knowledge. For this reason, the implementation of inductive grammar teaching offsets the implications of a more rule-driven teaching. This approach incorporates discovery-based learning as its core component. Discovery learning, first introduced by Jerome S. Bruner, is the "teaching and learning model in which students learn to recognize a problem, search for information relevant to the problem, develop a solution strategy, and logically justify the strategy." ${ }^{10}$ as means to achieve learning. Since this type of learning takes place when the target knowledge is unknown, the learner "must find it independently and with only the provided materials." "This way, students are required to think deeply about the specific content to be studied. ${ }^{12}$ Contrary to the deductive approach, inductive grammar teaching focuses on a rule-discovery learning process where learners' understanding of the structures is derived from examples without a previous implicit encounter with the rules. This implies learning through an experiential method in which the "exposure to a massive amount of input [makes] the regularities and patterns of the

8 Scott Thornbury, "How to Teach Grammar from Rules," How to Teach Grammar (Harlow, U.K.: Pearson Education Limited, 1999) 29.

9 Ali Hashemi and Samran Daneshfar, "The Impact of Different Teaching Strategies on Teaching Grammar to College Students", Theory and Practice in Language Studies 8, 3 (2018): 340-348 (342). DOI: http://dx.doi.org/10.17507/ tpls.0803.10.

10 D. C. Phillips, Encyclopedia of Educational Theory and Philosophy (California: Sage Publications, 2014) 236.

11 Louis Alfieri, Patricia J. Brooks, Naomi J. Aldrich and Harriet R. Tenenbaum, "Does DiscoveryBased Instruction Enhance Learning?," Journal of Education Psychology 103, 1 (2011): 1-18 (2). DOI: $10.1037 / \mathrm{a} 0021017$.

12 Phillips, 236. 
language become evident, independent of conscious study and explicit rule formulation." ${ }^{\prime 3}$ Moreover, Scrivener suggests that learning grammar through self-discovery engages and motivates learners to find generalized rules on their own. ${ }^{14}$ This mirrors the everyday natural learning process that occurs in an informal learning environment; that is, having a more inductively oriented EFL classroom facilitates learning grammar more naturally. ${ }^{15}$

The inductive grammar teaching approach views the learner as the most important entity of the teaching-learning process. Since students are closely involved in the discovery of rules and consequently in their own knowledge schemata construction, they must play an active role ${ }^{16}$ as part of their experiential learning. Therefore, from an inductive perspective, the teaching-learning process should be student-centered when studying grammar, rather than the traditional teacher-centered process. Mayer adds that generating knowledge by discovery skills putting into practice to unveil target grammatical rules and patterns makes the language learning process more memorable and effective for learners. ${ }^{17}$

As Widodo puts it, following an inductive approach to grammar teaching when dealing with pure rule discovery may lead language learners only to devise incorrect grammar rules and patterns. ${ }^{18}$ To avoid possible misconceptions, students must be guided throughout their learning process. To achieve this, Decoo proposed guided discovery as the modality of conscious induction. ${ }^{19}$ This allows learners to self-discover specific aspects of the language with the teacher's

13 Thornbury, 49.

14 Scrivener (2011), quoted in Soghomonyan,99.

15 Marcella Caprario, "Guided Discovery Grammar Instruction: A Review of the Literature with Original Teaching Materials." Thesis in TESOL. SIT Graduate Institute, 2013.

16 Mohammad Akram Alzu'bi, "Effectiveness of Inductive and Deductive Methods in Teaching Grammar," Advances in Language and Literary Studies 6, 2 (2015): 187-193. DOI: 10.7575/aiac. alls.v.6n.2p.187.

17 Mayer (2003), quoted in Alfieri, Brooks, Aldrich and Tenenbaum, 3.

18 Widodo, 128.

19 Decoo, 97. 
guidance. ${ }^{20}$ In this regard, Decoo explains that "The conscious discovery of the grammar is then directed by the teacher: on the basis of the examples he normally asks a few key-questions and the students are led to discover and formulate the rule." ${ }^{21}$ According to Alfieri, Brooks, Aldrich, and Tenenbaum, outcomes from the implementation of guided discovery are more significant and successful compared to those obtained from unassisted discovery or traditional explicit grammar instruction. ${ }^{22}$ For this reason, Glaser sustains that guided discovery is then "a central aspect for successful inductive language instruction." 23 Broadly put, guided discovery instruction not only exposes learners to the target grammar and elicits them to think deeply, but also guides the discovery process for effective results.

Additionally, guided discovery could be considered an indirect implicit intervention ${ }^{24}$ within grammar learning. Ellis et al. acknowledge that during implicit instruction, teachers need to provide learners with opportunities to discover rules on their own, based on data or context with no previous explanation of the grammatical structure. ${ }^{25}$ In addition, Alfieri et al. posit that for an effective instruction, it is essential to include at least one of the following aspects: scaffoldingguided tasks that elicit learners to explain their ideas and conclusions, task-modeling based on examples, and feedback to ensure accuracy. ${ }^{26}$ Moreover, Soghomonyan indicates that achieving student involvement in the discovery of grammar requires teachers to have a clear language objective and focus whether it is on meaning, form, use, or a combination of all of them. This author also considers that

20 Glaser, 60.

21 Decoo, 97.

22 Alfieri, Brooks, Aldrich and Tenenbaum, 13.

23 Glaser, 70.

24 Rod Ellis, Shawn Loewen, Catherine Elder, Rosemary Erlam, Jenefer Philp and Hayo Reinders, "Implicit and Explicit Learning, Knowledge and Instruction," Implicit and Explicit Knowledge in Second Language Learning, Testing and Teaching (Bristol, Buffalo and Toronto: Channel View Publications, 2009) 16.

25 Ellis, Loewen, Elder, Erlam, Philp and Reinders, 17.

26 Alfieri, Brooks, Aldrich and Tenenbaum, 13. 
text-based presentations are effective tools to contextualize learners with the language. At the same time, she proposes the incorporation of a series of questions and feedback to guide the learning process. ${ }^{27}$

To enhance guided discovery grammar learning in the EFL class, Widodo suggests building learners' knowledge of the target rules through the use of leading questions, conversations, or context. Consequently, this promotes communication and confidence among learners. Widodo also recommends including form-function exposure activities for students to apply the structure properly according to the specific context. This familiarizes learners with the rules and encourages their participation in the learning process. ${ }^{28}$ The type of activities proposed above gives teachers a clear panorama of the extent to which students understand and master the target item. At the same time, learners' performance and the outcomes of these activities shed light on the possible decisions that instructors are required to make to foster an effective learning. Widodo advises incorporating independent work to expand students' knowledge and reinforce the grammatical item studied. ${ }^{29}$ Using appropriate materials and implementing meaningful tasks that elicit learners to use rules and structures in context can facilitate the learning and internalization process of the grammar teaching points.

To provide learners with rule-discovery opportunities, authentic language context is considered the primary input source. Thus, structures are presented inductively in real language contexts for students to understand and learn the form and use, and also to practice the language in a contextualized setting. ${ }^{30}$ This way, one of the teacher's roles lies on the careful and systematic design of meaningful materials based on language context. ${ }^{31}$ Moreover,

27 Karina Soghomonyan, “Guided Discovery as an Inductive Way of Teaching Grammar,” 3, 21 (2016): 97-104 (99).

28 Widodo, 132.

29 Widodo, 137.

30 Soghomonyan, 98.

31 Widodo, 128. 
successful inference and discovery of patterns and rules "depend not only on how the data is organized, but on the quality and quantity of data itself." 32 Therefore, a thorough selection or design of the appropriate materials must be carried out.

In a communicative language teaching environment, grammatical mistakes are a common and natural part of learning. ${ }^{33}$ Thus, the focal point is the message conveyed regardless of the correct use of the rules. However, grammar, as a paramount component of the language, is strongly interrelated with communication and cannot be isolated from it. Conventionally, grammatical rules have been taught based on the teacher's direct explanation "without commencing to encourage learners to be involved in communicative tasks both written and spoken." 34 This has limited students' communicative skills and also has prevented them from shaping their knowledge through rule-discovery.

The implementation of guided discovery in the learning of English grammar benefits EFL learners. Westwood provides the following account of advantages that guided discovery has within the learning process.

1. Learners' active role in their own learning promotes intrinsic motivation.

2. Activities and techniques implemented are more meaningful compared to those found in traditional grammar teaching.

3. The reflective and investigative skills developed could be generalized and later implemented in different contexts.

4. Strategies and skills are not only applied but also learned in context.

32 Thornbury, 52.

33 Diane Larsen-Freeman, Techniques and Principles in Language Teaching (Oxford: Oxford University Press, 2000) 127.

34 Widodo, 30. 
5. Learning is based on students' previous knowledge and experiences.

6. Independent learning and teamwork are strongly fostered.

7. "It is claimed that students are more likely to remember concepts and information if they discover them on their own." 35 In the same line Soghomonyan sustains that "students learn better if they are involved in working something out for themselves, rather than just passively being told it." ${ }^{36}$

\section{Grammar Guided Discovery Learning Proposals}

Celce-Murcia and Larsen-Freeman point out that the teaching sequence of present, practice and produce, also known as PPP, has been commonly used to teach the grammatical component of the language. However, they acknowledge that this sequence is to be adapted according to the teaching approach selected and implemented; ${ }^{37}$ such is the case of guided discovery. They consider that the implementation of meaningful and consciousness-raising communicative tasks allows learners to induce and discover rules and patterns, and to come up with generalizations by themselves. ${ }^{38}$ Hence, the PPP method is effective in the guided discovery grammar learning process if its core principles are incorporated and developed. Soghomonyan suggests four key steps that comply with the characteristics of guided discovery using the teaching method of present, practice and produce.

35 Peter Westwood, What Teachers Need to Know about Teaching Methods (Victoria, Australia: ACER Press, 2008) 29.

36 Soghomonyan, 99.

37 Marianne Celce-Murcia and Diane Larsen-Freeman, The Grammar Book: An ESL/EFL Teacher's Course, $2^{\text {nd }}$ ed. (Heinle \& Heinle Publishers, 1999) 8.

38 Celce-Murcia and Larsen-Freeman, 8. 
1. First, teachers should know the content and focus, meaning, form, or use that students need to develop.

2. The content is introduced inductively to the learners; textbased presentations are considered to be more suitable for the purpose of guided discovery.

3. Then, students should be provided with activities or exercises that promote individual, pair, or group work.

4. The last stage of this proposal refers to the feedback and clarification of the grammatical rule or pattern provided by the teacher. ${ }^{39}$

Additionally, Westwood considers that for effective guided discovery learning, scaffolding is essential, and proposes the following five stages.

1. The target rule or pattern should be posed first; this can be presented through the use of different materials and contexts.

2. Together, teacher and learners, brainstorm ideas about the respective topic; however, students take an active role and the teacher only guides the process.

3. Individual or group work must be conducted to analyze information; this entails the development of learners' cognitive skills.

4. This cognitive process results in students' inferences and tentative conclusions that can be modified along the learning process.

5. Similar to Soghomonyan, Westwood indicates that in the last stage of guided discovery learning, the instructor guides learners by clarifying misunderstandings and misconceptions. ${ }^{40}$

In the present study, the steps suggested for guided discovery learning in the study of English grammar were implemented following the PPP teaching method.

39 Soghomonyan, 99.

40 Westwood, 29. 


\section{Analyzing and Reasoning Strategies}

Discovering a specific grammatical rule based on a concrete language context entails that learners go through an in-depth cognitive process; this mental effort, of course, requires deeper cognition levels and assures better memorability ${ }^{41}$ For instance, allowing students to put into practice inferring, inducing and reasoning abilities enables the development of pattern-recognition, problem solving and critical thinking skills. ${ }^{42}$ Since grammar knowledge is selfconstructed, “... greater learning, comprehension, and/or retention. . . [are to be achieved; therefore,] learning by discovering seems to require a greater number of mental operations, as well as better executive control of attention." ${ }^{\prime 3}$ Thus, guided discovery learning involves preparing students to be able to develop mental operations for the self-discovery of rules. For this reason, instructors must provide learners with the necessary tools.

Learning English grammar through discovery requires the use of learning strategies. This term refers to "what learners do in order to make their learning manageable and efficient." ${ }^{\prime 4}$ Oxford explains that learning strategies are divided into two main classes, direct and indirect, ${ }^{45}$ which are to be used in the language learning process. However, this study deals with the direct cognitive strategies exclusively.

Because guided discovery encourages learners to find grammatical rules and patterns, applying this type of cognitive strategies is vital. This group belongs to the broad set of direct strategies that deal directly with the language. According to Oxford, the two most important categories of this set are reasoning deductively and

41 Thornbury, 54.

42 Caprari, 17.

43 Alfieri, Brooks, Aldrich and Tenenbaum, 3.

44 Višnja Pavičić, Vocabulary Learning Strategies and Foreign Language Acquisition (Wilshire, U.K.: Cromwell Press, 2008) 2.

45 Rebecca L. Oxford, “Applying Direct Strategies to the Four Language Skills," Language Learning Strategies: What Every Teacher Should Know (New York: Newbury House Publisher, 1990) 14. 
analyzing expressions; both intend to make use of logical thinking in order to reason, "understand and use the grammar rules... of the new language." ${ }^{\prime 6}$ On the one hand, the former strategy elicits the formulation of hypotheses based on prior knowledge; nonetheless, this can also take place when encountering new contexts. On the other hand, the latter-analyzing expressions - refers to the separation of items, words, phrases or sentences to understand expressions and grammatical structures. Allowing learners to apply these cognitive strategies while learning grammar through guided discovery promotes, to a great extent, the development of analyzing and reasoning skills. These are fundamental in the learning process because they provide students with more autonomy to self-regulate and shape own knowledge.

\section{Methodology}

\section{Research Design}

For the purposes of this study, action research under the qualitative paradigm was selected to improve the instructor-researcher's current grammar teaching practices that subsequently impact students' learning. As Tomal explains, this type of research "is a systematic process of solving educational problems and making improvements... within the context of study." ${ }^{\prime 7}$ For this reason, action research has been commonly used in the field of education as a way to achieve teaching goals more effectively. ${ }^{48}$ In addition, Latorre states that conducting it not only seeks for the improvement of current practices and their better understanding but also allows teachers

46 Oxford, 82.

47 Daniel R. Tomal, "The Nature of Educational Research," Action Research for Educators (Lanham, Maryland: Rowman \& Littlefield Education, 2010) 10-11.

48 Robert P. Pelton, "An Introduction to Action Research," Action Research for Teacher Candidates: Using Classroom Data to Enhance Instruction (Lanham, Maryland: Rowman \& Littlefield Education, 2010) 3. 
to become active researchers in their own teaching environment. ${ }^{49}$ Pelton sustains that action research is "a powerful mindset for teaching because it emphasizes [the teacher's] ... role as a reflective practitioner who is continually observant, thoughtful, and willing to examine personal action in the light of the best possible practices for... students. ${ }^{\prime 50}$ Therefore, conducting this study develops a sense of introspection on the part of the instructor-researcher that can be reflected in the teaching and learning process in the study of grammar.

\section{Context of the Study and Participants}

The present research was carried out for five months during the first semester of the 2019 schoolyear in an English course intended for students of different majors. This course incorporates the four language skills, speaking, listening, reading, and writing, as well as grammar and vocabulary in an integrated manner. To conduct the study, a total of 26 students were taken into account. This group of learners has different educational backgrounds; for instance, 15 of them had studied in public academic high schools, 5 in public bilingual high schools, 3 in a public technical institution, and 3 in private high schools. Moreover, 8 of these learners have studied English in other institutions in addition to the lessons received in high school. Nonetheless, this English course is the first one at the university level for all of these participants.

\section{Data Collection Instruments}

A variety of data collection instruments and techniques were used to gather the necessary information. In order to know the students' perceptions about English grammar learning and their previous learning experiences as well as their perspectives after the

49 Latorre, 27.

50 Pelton, 3. 
implementation of grammar guided discovery, two questionnaires were administered to the participants, one at the beginning of the study and the other one at the end. Furthermore, seven class participant observations were conducted. The initial questionnaire and the first observation served the purposes of the diagnostic stage of the research. As to the rest of the participant observations, they explored the instructor-researcher's teaching practices and the students' performance during the implementation of guided discovery. These class observations were recorded in an instructor-researcher journal for analysis and reflection. Additionally, the document analysis technique was implemented to examine the documentary evidence "in order to gain meaning and empirical knowledge of the construct being studied." ${ }^{51}$ In this case, the materials selected and designed by the instructor-researcher to teach the grammatical contents during each session were analyzed.

\section{Procedures}

For this action research study, the Kemmis' model was followed. This is characterized by having four main stages: the action plan, its implementation, observation, and reflection. This cyclical process starts with the development of an action plan to be implemented and observed for later reflection upon its outcomes. ${ }^{52}$ Townsend indicates that the results obtained from each cycle become the groundings for the next cycle of the research. ${ }^{53}$ Furthermore, Pelton suggests that an action research study begins with the identification of the problem in the initial diagnostic stage before studying it in depth. ${ }^{54}$ As part of this diagnostic stage, the instructor-researcher used a previous

51 Bruce B. Frey, The SAGE Encyclopedia of Educational Research, Measurement, and Evaluation (Thousand Oaks, CA: SAGE Publications, 2018).

52 Kemmis (1989), quoted in Latorre, 35.

53 Andrew Townsend, "The Processes of Action Research," Action Research: The Challenges of Understanding and Changing Practice (Berkshire: McGraw Hill. Open University Press, 2013) 14.

54 Pelton, 8-9. 
introspection of current teaching practices to identify the need to provide the learners with opportunities to develop reasoning and analyzing skills in the learning of grammar. In addition, the data collected from the diagnostic class observation and the first students' questionnaire were the building blocks for the action plan and the upcoming stages of the research process. Moreover, the present study was divided into two complete reflexive cycles with the four stages mentioned above. Each cycle included three sessions based on the presentation, practice and production (PPP) teaching method following guided discovery according to the grammatical contents to be studied within the course. Both cycles had three different sessions each of which focused on specific forms. During these sessions, only one grammatical content item was developed. In the first cycle, the third person singular structure, present progressive, and simple past tense were studied whereas the second cycle included the used to structure, present perfect and past perfect.

\section{The Action Plan}

Based on the findings of the diagnostic stage, the first students' questionnaire and the initial class observation, the instructor-researcher elaborated action plan to promote analyzing and reasoning skills through a guided discovery grammar learning process. Therefore, to conduct this intervention, teaching practices were to follow the main tenets of guided discovery that elicit learners to analyze and reason as means to self-discover rules and patterns. The instructorresearcher selected a variety of teaching materials for the presentation, practice and production of these structures in the English class.

The intention of the first stage of this action plan, the presentation phase, is to familiarize students with the grammatical teaching points in an implicit manner by presenting the structures through contextualized activities such as games, discussion questions, songs, and listening comprehension exercises. Also, this phase consisted 
of presenting short paragraphs and sets of sentences that contained the target forms for learners to analyze within context. The purpose of the analysis was for the students to find patterns and discover rules from the given context on their own. To guide this analytical process and help learners organize their findings, the instructorresearcher designed a graphic organizer template for each session. According to Parker, a graphic organizer is a visual representation that does not only allow students to collect and sort information but also enables them to identify "patterns and relationships between the given information." ${ }^{55}$ After conducting the analysis of the grammatical items in context, the students filled out these graphic organizers based on the patterns found and rules they previously discovered. The learners' general conclusions and findings gathered through the use of graphic organizers were discussed and shared as a group. Then, the learners' ideas were expanded by the instructor-researcher's guided explanations at the end of this presentation phase. As for the practice stage, the students were provided with error correction and completion exercises to practice the different rules studied. Finally, the production phase aimed to apply the structures and their rules in contextualized tasks. Participating students were not explicitly informed about what discovery learning is, but rather guided through the discovery process. The teacher-researcher instructed the learners how to conduct context analysis by using guiding questions and examples, and explained how to use graphic organizers as a tool to record findings and conclusions derived from the analysis.

Due to the nature of action research, once this plan of action was implemented, observed, and reflected upon during the first cycle, several modifications were made to enhance a better grammar guided discovery learning in the second cycle.

55 Christi E. Parker, 30 Graphic Organizers for the Content Areas (Huntington Beach, CA: Shell Educational Publishing, 2006) 4. 


\section{Analysis of Results}

In this section, the data collected from the students' questionnaires, the class observations, and the teaching materials are analyzed. The intention of this analysis of results is to explain the implications of guided discovery in the learning of grammar. Data from this action research study are presented qualitatively and quantitatively to provide results more comprehensively.

\section{The Diagnostic Stage}

The data collected from the diagnostic stage allowed the instructor-researcher to gain a general understanding of the students' perceptions about grammar learning, their previous learning experiences, and their performance when implementing guided discovery.

Taking into consideration the results from the questionnaire, it was found that these students have different perceptions as to what grammar learning is. They indicated that learning English grammar is filling out written exercises, memorizing rules, listening to the instructor's direct explanations, and discovering rules and patterns. As shown in figure 1, for them, the main way of learning the grammatical component is by discovering rules and patterns. Additionally, completing written exercises and memorizing rules are equally considered the second means for grammar learning. Listening to the instructor's direct explanations is the last resource to learn the grammatical structures of the language. Nonetheless, interestingly enough, it was found that over $80 \%$ of the students considered that listening and paying attention to these direct explanations is more effective than discovering rules on their own. In fact, 21 students stated that English grammar is learned better through direct explanations from the instructors, and 5 reported discovering rules as the best way. 
Figure 1: Students' Perspectives about Grammar Learning

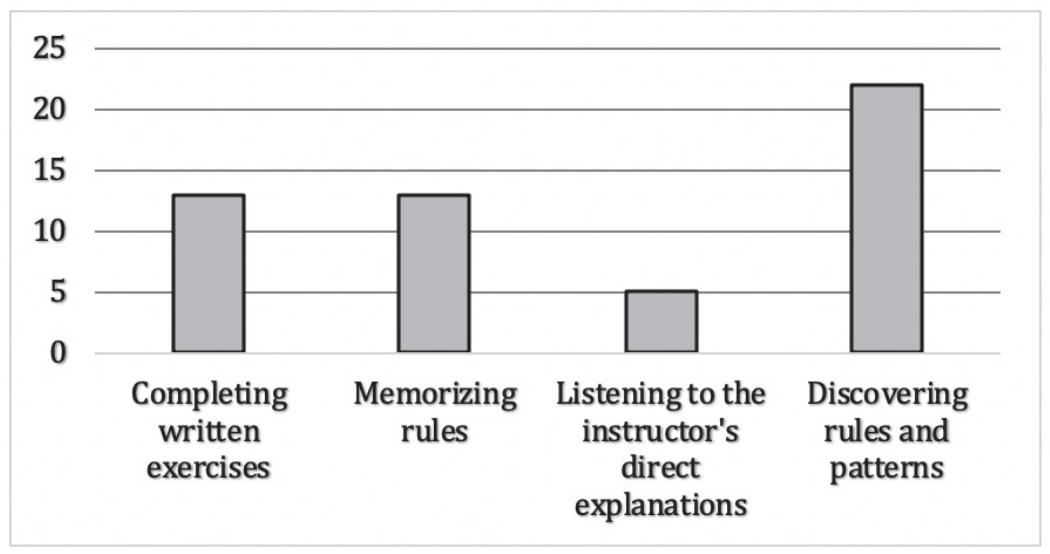

Source: Based on results from the students' first questionnaire.

Regarding the previous grammar learning experiences of the participating students, figure 2 shows that they mainly learned the rules by filling out written exercises. Furthermore, results also indicate that the students had learned grammar by memorizing rules, listening to their instructors' direct explanations, and discovering rules and patterns. In addition, when asked about the most common grammar teaching practices of their previous instructors, the learners stated that their teachers used traditional direct explanations and written exercises from textbooks or additional materials. Twenty-two participants believed that how they were previously instructed elicited and fostered analyzing and reasoning skills in their learning process.

As figure 1 and figure 2 show, the students' perceptions about grammar learning and their previous learning experiences differ. The most salient finding is that contrary to what the students believe grammar learning is - discovering rules and patterns (see figure 1) they said that they had mainly learned the rules by filling out written exercises instead. Although listening to direct explanations was considered the least prominent way to learn grammar, the students 
reported that when it comes to their own learning experience, it was used as much as memorizing and discovering rules.

Figure 2: Students' Previous Learning Experiences

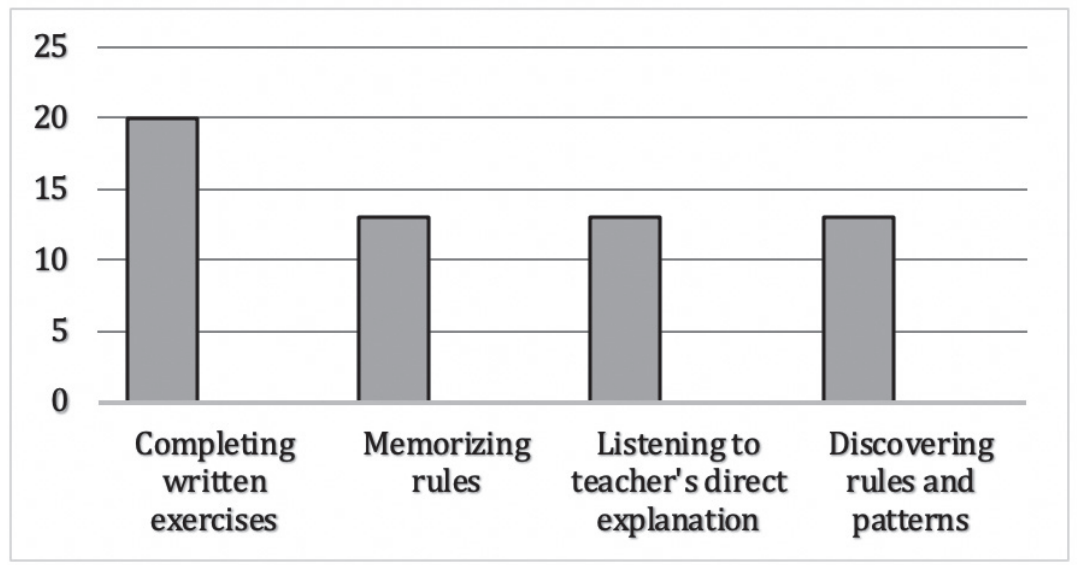

Source: Based on results from the students' first questionnaire.

It is clear then that for these students learning the grammatical structures of the language mostly entails discovering patterns and rules on their own; however, this was not evident during the diagnostic lesson observed. It was found that the students' analyzing and reasoning skills required more development to attain an effective grammar discovery learning process. Identifying the simple present structure within context, in this case a short paragraph about daily routines, was a difficult task for the learners. For instance, at the beginning of the session, they did not know how to analyze the text to identify the specific patterns, but rather focused on content and vocabulary. After studying the written context in depth, the students discovered only a few patterns and some specific rules of the target structure. Additionally, the learners found it difficult to complete a graphic organizer with the rules they previously discovered. While identifying the rule and organizing ideas, they asked the instructor to 
confirm their possible findings and explain the rules for them. This reflects the traditional explicit grammar teaching that these students have undergone and the teacher-dependent learning practices that they have acquired during their learning process. It also shows that the students' perceptions and current learning practices are inconsistent when it comes to the study of grammar.

\section{First Cycle}

Once the plan of action was implemented and observed, the data gathered from the reflection stage were used for the analysis of this action research study. For the purposes of this study, three main aspects of the grammar teaching and learning process through guided discovery were identified and analyzed: the students' performance, the educator's instruction, and the teaching materials used.

\section{Students'Performance}

At the beginning of the first cycle, the students were provided with instructions about how to analyze written texts to identify patterns and formulate rules from them. However, once the learners were requested to analyze the context and complete the graphic organizers template based on their findings, it became a challenge for them. In fact, during the first two sessions of the cycle, the students struggled to find common patterns and discover complete rules within context. To overcome these difficulties, the students asked the instructor to help them identify patterns, clarify components of the rules, and confirm the possible rules found. This prevented them, to a great extent, from applying reasoning and analyzing skills as a means of drawing general conclusions for a better understanding of the grammatical contents. In addition, their reliance on the instructor's direct grammatical explanations limited them from finding ways to discover the rules on their own based on 
the context examined. Nonetheless, during the last session, it was observed that their performance, compared to that of the other two sessions, had slightly improved. They had a better understanding of the context analysis and the graphic organizer completion process and depended less on the instructor to find answers to their own questions. Yet, their overall performance throughout this first cycle was not as expected. Therefore, their analyzing and reasoning skills need to be strengthened to achieve a more effective grammar selfdiscovery learning.

\section{Teacher's Instruction}

The reflection of the teacher-researcher's instruction is an essential aspect of the present study. This allowed to understand the impact reflection has on the grammar learning process, and subsequently raise awareness on the necessary changes required for improving the teaching practices. For this reason, this section sheds some light on the contribution and areas of improvement of the current grammar teaching practices in the implementation of guided discovery learning.

On the one hand, the core principle, student-centeredness, was adopted along the first cycle of the research. Thus, the learners became the most important participants of their knowledge construction process whereas the instructor-researcher became the facilitator and guide. In this role, following the main tenets of the guided discovery learning, the instructor made use of scaffolding to guide learning throughout the process instead of implementing an inductive grammar teaching approach. For instance, the instructor-researcher implicitly presented the grammatical structures in context through the use of activities and written texts. These structures were then analyzed and practiced by the students without previous direct traditional explanation. Correcting mistakes and providing individual feedback during the completion of exercises and tasks were part 
of the grammar lessons; however, the sessions did not devote much time to the analysis and self-correction of their mistakes. Although guiding questions were used to help the learners find answers to their questions, and analyze patterns and rules, some concrete answers were provided as well. This limited the students' ability to reason and find possible answers by themselves. Furthermore, the learners did not have active participation while orally sharing findings from the analysis. Because of this, the instructor-researcher used some students' ideas and examples to give general explanations of the grammatical structures for the whole group. Based on the previous reflections, it was found that more efforts were to be made regarding the educator's instruction to attain a guided discovery learning that pursues more reasoning and analyzing from the students themselves.

\section{Teaching Materials}

The third aspect reflected upon in this study was the teaching materials used for the three sessions in the cycle. In guided discovery, context plays a significant role because it is the point of departure in the process. For this reason, exposure to the grammatical structures during the initial stage allowed the students to direct their attention to the target structures and become acquainted with them within context, even if they had not been introduced previously. As for the presentation phase of the sessions, the instructor-researcher selected and designed materials such as a Bingo game, lyrics completion exercise, written conversations, discussion questions, and short paragraphs. For each session, one of the materials mentioned above was used to present the structures implicitly. A short paragraph for each grammatical content was also used for analysis purposes. Based on the results of the document, it was found that the written texts - the short paragraphs - used for the analysis of the grammatical structures analysis gave the learners a better understanding of the form, meaning, and usage of the specific grammar teaching points. 
Nevertheless, the fact that these texts did not contain an account of all the components of the rules and their possible variations could be considered a downfall since it did not let the learners have a complete view of those rules. Moreover, although every paragraph contained the structures within context, the specific structure for the session was not clearly evident for them. Consequently, the learners spent more time focusing only on the analysis of the texts, reducing time for practice and production. In addition, not highlighting or specifying the structures to be studied in the context made the learners be easily distracted analyzing elements that were out of the scope of the lesson. Other documents analyzed were the graphic organizer templates designed for the learners to complete according to the findings of the context analysis. These grammar worksheets were part of the presentation phase. They guided the students by directly asking them for the specific information to be included without posing guiding questions to analyze and answer based on the context previously examined. In the case of the practice stage, error correction and completion exercises were chosen from the textbook and other teaching resources. They provided opportunities to practice the specific rules discovered. Likewise, the analysis of the documents indicated that the instructor and the teaching materials also had areas of improvement to facilitate the discovery process for the learners.

\section{The Revised Action Plan}

Upon reflection, several adjustments were made to the action plan with regard to the educator's instruction and the teaching materials used in class. Regarding the former, the instructor-researcher had to point out specific examples of the rules within the texts and made use of guiding questions to promote a more self-discovery type of learning, for the students to be able to find answers on their own instead of seeking direct answers from the instructor. It was also essential to allow the students to analyze texts, and to compare 
and share findings with other learners as a means of promoting cooperative learning rather than relying only on the instructor. This was seen in the presentation phase of the sessions, specifically during the completion of the grammar worksheets (graphic organizer templates) and the explanations of findings. The intention was both to prevent the instructor-researcher from giving direct grammatical explanations and also to expand on the learners' explanations only if it was strictly required. Additionally, since guided discovery learning focuses on students, they must participate actively when general feedback is given. Therefore, mistakes recorded from the different tasks were to be spotted and corrected by the students, not just by the instructor. As for the latter aspect, the teaching materials used, it was crucial that the written texts selected for the context analysis included possible variations of the rules and all of the elements of the grammatical structure. Hence, the students were able to conduct a thorough analysis of the patterns and rules. Moreover, the specific structures studied were to be highlighted within the text not only to reduce the time of completion but also to focus the students' attention on a specific grammatical topic. In terms of the grammar worksheets, it was essential for the graphic organizer templates to guide the learners without explicitly instructing them what to include. This was to be achieved by incorporating guiding questions in this material as well. The intention of these overall modifications of the action plan was to enhance grammar guided discovery learning to a greater extent during the following cycle of the research.

\section{Second Cycle}

Taking into consideration the modifications provided in the reflection stage of the first cycle, the action plan was revised and improved. Once the revised action plan was implemented and observed during the second cycle, it was also analyzed in terms of the 
students' performance, the educator's instruction, and the teaching materials used.

\section{Students'Performance}

In contrast to the first cycle, it was found that the students' performance improved overall during the sessions of the second cycle. The data gathered from the observations revealed that the students could derive more rules by themselves, find additional answers to their questions, correct their own mistakes, ask fewer questions, and request less direct explanations from the instructor. It was also generally observed that the learners paid closer attention to the exercises by carrying out deeper analyses of the items. The students showed more autonomous learning practices, and better analysis and reasoning skills. Moreover, findings suggest that this group of learners had a more participative role throughout the sessions. For instance, the students not only shared their findings from the context analysis with their peers, but they also had discussions that delved deeper into their ideas. Thus, the learners were able to support conclusions analytically. Along the constant self-discovery process that the students were part of, less time was devoted to text analysis and completing the graphic organizers. This allowed more time for the practice and production stages. Even though their rule self-discovery learning practices improved significantly, a small group of learners still needed the instructor's confirmation of their findings and direct explanations for clarification.

\section{Educator's Instruction}

It was found that this cycle provided more relevance to the students during the teaching and learning process in order to move away from a teacher-centered environment to a more student-centered one. This was evident at three different levels in regard to the 
educator's instruction. First, as in the previous cycle, the educator's role was to guide and monitor the learners; nonetheless, for this second cycle the instructor-researcher incorporated different strategies to guide the process. For instance, instead of providing direct explanations and answers to the students' questions, examples were given and guiding questions were posed. At the same time, the learners' attention was directed to specific aspects of the context analyzed. Consequently, their analyzing and reasoning skills were put into practice when looking for possible answers on their own. Based on the lessons observed, a more guided learning process for the students was attained since the activities were developed in scaffolding. Second, having the students share and explain findings from the context analysis, and expanding on grammar teaching points only when necessary also contributed to student-centeredness. This facilitated their construction of knowledge cooperatively through guided discovery learning of grammar. Third, the learners were provided with opportunities to reflect and correct their own mistakes. This allowed them to be more responsible for their own learning, and also helped them to develop self-regulating and monitoring skills.

\section{Teaching Materials}

For the previously selected and designed teaching materials to comply with core tenets of the guided discovery learning, several modifications were made to the action plan. During the presentation phase, a prior knowledge quiz (about past and present), a listening exercise, a game of "Find Someone Who," and a past-tense story listening exercise were used to present the students with the grammatical structures implicitly. In terms of the context analysis, a short paragraph and sets of contextualized sentences were used. These texts had the structures highlighted, which made the analysis easier for the learners. In this way, the students were not distracted with other elements from the texts since they focused specifically on 
the target structures. Moreover, including variations of these structures helped the learners gain a broad understanding of the rules. This prevented them from speculating on possible variations as they drew conclusions and supported findings. Furthermore, the revision of the improved worksheets showed that the incorporation of guiding questions in the graphic organizer templates was intended to promote thinking skills in the students.

\section{Students' Perspectives about Grammar Guided Discovery}

After implementing guided discovery in the study of grammar, it was considered necessary to delve into the students' perspectives and experiences by administering the second questionnaire. Similar to the results obtained from the first questionnaire, it was found that at the end of the study the majority of the learners deemed that learning the grammatical component of the language is discovering rules and patterns on their own. Overall, these participants shared common ground with respect to what this type of learning entails based on their experience during the course. They reported that grammar discovery learning consists of comparing rules and finding possible differences, identifying and understanding patterns within context, questioning themselves, inquiring about patterns from written texts and analyzing their function, discovering patterns and understanding their use, and analyzing different texts and their grammatical structures in depth.

According to the results from the questionnaire, 22 of these students indicated that the activities implemented in the class fostered grammar discovery learning. As to whether these activities promoted analysis and reasoning skills, 21 of the learners concurred that this inductive approach to grammar teaching and learning developed these skills to a great extent. When asked if they liked learning grammatical structures through self-discovery, 18 participants stated that they did. Asked whether they prefer to study grammar through 
guided discovery or not, 15 of them agreed that they did while the rest of the learners preferred a traditional deductive approach based on the instructor's grammatical direct explanations. In regard to the achievements obtained, as shown in figure 3 , the students indicated that guided discover learning has brought great benefits for them. According to the participants, the implementation of guided discovery firstly helped them to develop better monitoring and self-correction skills. Then they considered the development of analyzing and reasoning skills as their second achievement. With respect to the third attainment, they recognized that they had achieved a more autonomous grammar learning process. Lastly, these students indicated that they had become less dependent on the instructor's deductive explanations and direct answers.

Figure 3: Students' Achievements

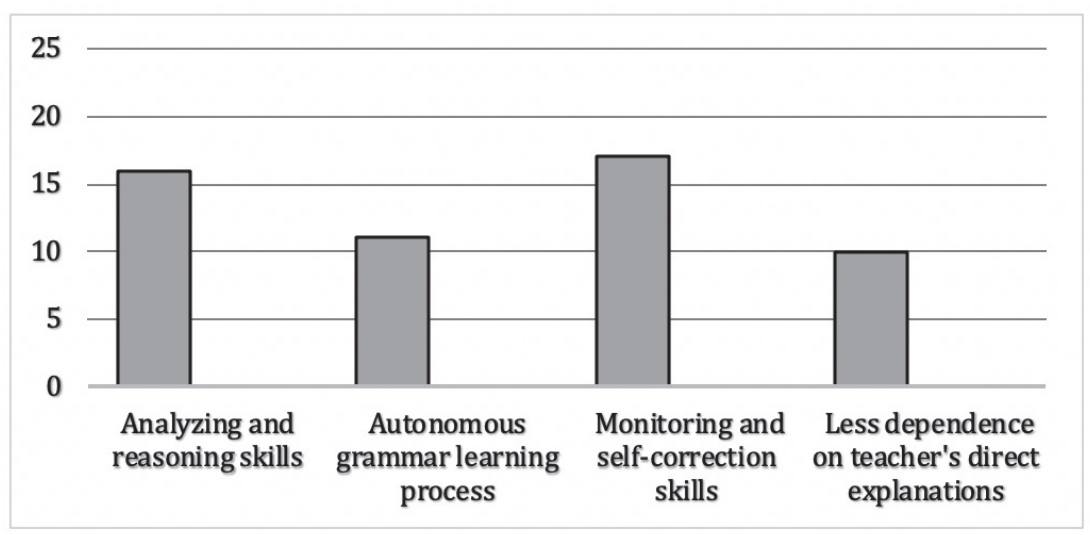

Source: Based on results from the students' second questionnaire. 


\section{Conclusions}

All in all, after completing this cyclical action research study, some general conclusions were drawn in regard to the implementation of guided discovery in the study of grammar in the EFL class.

At the beginning of the study there was a mismatch between what the participating students know and understand as grammar learning and what guided discovery entails in the practice. Although the students considered that learning grammar is discovering rules by themselves, this was not observed in the diagnostic stage of the study. However, findings suggest that by the end of the study the gap between the students' learning practices and their perceptions was bridged. The implementation of guided discovery during the research cycles not only developed discovering skills among the students but also allowed them to put into practice what they truly considered grammar learning is. Nonetheless, learning grammar through guided discovery was not an easy task for these learners. In fact, they struggled to analyze grammatical structures within context and discover rules on their own. The difficulties they showed finding patterns and formulating rules on their own, especially during the first cycle's sessions, confirmed that traditional deductive grammar teaching has been these students' prevailing way of learning the grammatical component of the language. It is clear then that the students were not provided with real opportunities to self-discover rules during their previous English grammar learning experiences. Even though guided discovery learning was difficult for these learners at first, it was well accepted and valued by them. According to the learners' responses in the last questionnaire, the majority of them indicated that they enjoyed and appreciated learning the grammatical contents through the use of guided discovery. In the same vein, taking into consideration the students' experience during the course, they acknowledged that they prefer to self-discovery over listening to teacher-oriented direct explanations. 
Based on the findings of this action research study, it was concluded that guided discovery had impacted the students positively. Since the learners were able to apply analyzing and reasoning strategies constantly during the cycles, these skills were effectively fostered during the implementation of the presentation, practice and production (PPP) teaching method in the light of guided discovery. Moreover, implementing guided discovery practices in this English course not only acquainted the learners with self-discovery but also allowed them to adopt it as a way of learning grammar. As the students themselves pointed out, another advantage of guided discovery is that they developed monitoring and self-correction skills in their own learning process. Studying the target grammatical structures cooperatively, therefore, provided a better understanding of the rules and promoted a more active and efficient participation among the students. This strengthened confidence and enabled them to support their findings and ideas. The implementation of this type of learning in the EFL class also developed the students' sense of autonomy. Consequently, this enabled them to rely less on the instructor's deductive explanations and became the key agents in their own ongoing learning process.

Another major conclusion of this study is the paradigm shift of the instructor-researcher's current grammar teaching practices. Being taught and teaching others grammar following the traditional deductive approach is a common practice for many English teachers, and for the instructor-researcher of this inquiry. Conducting this reflective study raised awareness of the relevance that reflection has in the teaching process. It also shed light on the need to explore teaching practices objectively and constantly to solve educational problems and improve such practices. Thus, due to the regular reflection conducted during the cycles of the research, different areas of improvement were identified and addressed in the revised action plan. The intention was to enhance the teaching and learning process at different levels: (1) the educator's instruction, (2) the students' 
performance, and (3) the teaching materials designed and used. Indepth introspection in the different stages of this cyclical study enabled the instructor-researcher to make the necessary adjustments to the action plan in instruction and the teaching materials used to attain better results in grammar learning.

The present study acknowledges the urgent need for students to develop analytical and reasoning skills while learning grammar in an EFL class. Therefore, the aim of this paper is to motivate other English teachers to reflect upon their own grammar teaching practices and the impact they have on their students' learning. Conducting introspection on a regular basis makes it possible to identify practices that may hinder the development of learners' thinking skills. It also allows teachers to modify their everyday instruction to provide students with tools and create opportunities for a more analytical and autonomous type of learning. 